\title{
A reforma agrária como ferramenta para o desenvolvimento rural sustentável no assentamento Valmir Mota em Cascavel, Paraná
}

\section{Agrarian reform as tool for sustainable rural development in Valmir Mota settlement in Cascavel, Paraná, Brazil}

\begin{abstract}
Marlowa Zachow $\mathbb{1}^{1}$, Alan Denizzar Limeira Coutinho², Jaqueline Gomes Demarchi Grisa ${ }^{3}$, Márcia Andréia Barboza ${ }^{4}$ Patricia Ines Costa ${ }^{5}$, Paulo Alexandre Laskosk ${ }^{6}$

${ }^{1}$ Doutoranda em Desenvolvimento Rural Sustentável, Universidade Estadual do Oeste do Paraná, Marechal Cândido Rondon, +554598403-5323, marlowaz@hotmail.com, ${ }^{2}$ Doutorando em Desenvolvimento Rural Sustentável, Universidade Estadual do Oeste do Paraná, Marechal Cândido Rondon, cndenizzard@yahoo.com.br; ${ }^{3}$ Mestranda em Desenvolvimento Rural Sustentável, Universidade Estadual do Oeste do Paraná, Marechal Cândido Rondon, jaquelinegdemarchi@hotmail.com; ${ }^{4}$ Mestranda em Desenvolvimento Rural Sustentável, Universidade Estadual do Oeste do Paraná, Marechal Cândido Rondon, marciaandreiabarbozasilva@gmail.com; ${ }^{5}$ Doutoranda em Desenvolvimento Rural Sustentável, Universidade Estadual do Oeste do Paraná, Marechal Cândido Rondon, patriciainescosta@hotmail.com; ${ }^{6}$ Mestrando em Desenvolvimento Rural Sustentável, Universidade Estadual do Oeste do Paraná, Marechal Cândido Rondon, alexandre laskoski@ hotmail.com
\end{abstract}

\section{A R T I G O}

Recebido: 04/11/2019

Aprovado: 19/11/2019

Palavras-chave:

Objetivos de desenvolvimento

sustentável

Sustentabilidade

Movimento sem terra

Key words:

SDG

Sustainability

Landless movement
RE S U M O

O Movimento sem terra (MST) surgiu como forma de lutar pela terra e pela reforma agrária, bem como promover o desenvolvimento sustentável. A Organização das Nações Unidas (ONU), por sua vez, tem trabalhado em 17 objetivos para o desenvolvimento sustentável. Através de um estudo de caso, buscou-se entender como a reforma agrária pode promover o desenvolvimento rural sustentável no Assentamento Valmir Mota de Oliveira, na cidade de Cascavel no Oeste do Paraná. Foi verificado que o Assentamento desenvolve várias práticas de sustentabilidade, atendendo 8 dos 17 objetivos do desenvolvimento sustentável propostos pela ONU.

\section{A B S T R A C T}

The Landless Movement (MST) emerged as a way to fight for land and land reform, as well as to promote sustainable development. The United Nations (UN), for its part, has been working on 17 goals for sustainable development. Through a case study, we sought to understand how land reform can promote sustainable rural development in the Valmir Mota de Oliveira Settlement, in the city of Cascavel in western Paraná. It was found that the Settlement studied develops various sustainability practices, meeting 8 of the 17 goals of sustainable development proposed by the UN.

\section{INTRODUÇÃO}

A reforma agrária reflete a esperança pela distribuição de terras, o sonho do direito ao seu meio de produção. A política de reforma agrária trata de uma re-territorialização, em que o principal responsável seria o Estado, aliado com a luta do povo (SANTOS, 2017). No Brasil, a reforma agrária está marcada pela maneira de produção do sistema colonial português, baseado em exploração de recursos ambientais em grandes áreas rurais. Na época da colonização quem tinha acesso as terras era quem tinha melhores condições financeiras (SILVA et al., 2016).
A reforma agrária surge como reinvindicação dos camponeses no Brasil a partir da década de 1950 em vários pontos do país, através de grupos organizados conhecidos como Ligas Camponesas, influenciados por outros grupos que também demonstravam interesse nessa pauta, incluindo a Igreja, os sindicatos e partidos políticos, em especial o Partido Comunista Brasileiro (PCB) (MARTINS, 1981). Segundo o Estatuto da Terra, documento criado em 30 de novembro de 1964 pelo Governo Militar, para viabilizar um desenvolvimento agrário para o país, em seu art. 1 , "§ $1^{\circ}[\ldots]$ O conjunto de medidas que visem promover a melhor distribuição da terra, mediante modificações no regime de sua posse e uso, para
Revista Verde

ISSN 1981-8203

Pombal, Paraíba, Brasil v. 14, n.5, Edição Especial, p.597-602, 2019

doi: $10.18378 /$ rvads.v14i5.7396 
atender aos princípios de justiça social e ao aumento de produtividade" (BRASIL, 1964).

As lutas pela terra feitas pelas Ligas Camponesas, nas décadas de 1950 e 1960, assim como pela Comissão pastoral da Terra na década de 1970, viabilizaram a estruturação dos movimentos sociais rurais, inclusive o Movimento Sem Terra (MST) (SILVA et al., 2012). Em 1984 surge então o MST, fruto da articulação dos trabalhadores, o qual possui os seguintes princípios: lutar pela terra, pela Reforma Agrária e por uma sociedade mais justa, sem exploradores e explorados.

As discussões sobre a necessidade de um desenvolvimento sustentável para o campo estão presentes em diferentes áreas da produção científica, que discutem a situação agrária do país. A ideia de que o campo precisa ser pensado de forma a diminuir as injustiças sociais, priorizando a produção de alimentos sem o uso de agrotóxicos, é pauta também dos objetivos elencados pela Organização das Nações Unidas (ONU), que propôs em 2015, a implantação dos Objetivos de Desenvolvimento Sustentável (ODS), com o intuito de ampliar os Objetivos de Desenvolvimento do Milênio (ODM) que na época eram compostos por 8 tópicos, e atualmente são compostos por 17 objetivos.

Os 17 objetivos propostos pela ONU buscam reduzir a pobreza, para proporcionar a todas as famílias prosperidade e bem-estar, além disso, tem como intuito conservar e preservar o meio ambiente, onde se faz necessário manter a igualdade para a sociedade e o desenvolvimento sustentável. Além dos 17 objetivos, existem 169 metas que auxiliam a alcançar tais medidas sem se desviar do objetivo principal, visando os três pilares do desenvolvimento sustentável, o ambiental, o social e o econômico. Esses objetivos devem ser atingidos até 2030 (agenda 2030), onde se busca viver em um mundo livre da pobreza, fome, doença e penúria, buscando levar uma alimentação nutritiva segura e saudável a população mundial. As medidas buscam também proporcionar a sociedade uma vida livre do medo da violência no campo, responsável por gerar sérios problemas à sociedade, buscando também assegurar uma educação de qualidade de forma igualitária, água potável e saneamento básico para que todos possam ter uma vida digna, buscando também, levar a toda população energia acessível, confiável e sustentável (ONU, 2018).

O surgimento do MST foi considerado um movimento de inclusão social da classe camponesa, que teria como objetivos: eliminar a pobreza; combater a desigualdade social; garantir trabalho, educação e renda no campo; garantir a soberania alimentar nos mercados locais; garantir a participação igualitária das mulheres nas decisões de uso da terra; manter e preservar a biodiversidade vegetal, animal e cultural de cada região; garantir a permanência dos jovens no campo através da promoção de renda, educação, moradia e lazer (SILVA et al., 2016). Todos esses objetivos podem ser considerados como metas para o desenvolvimento sustentável, que estão transcritos em alguns dos objetivos determinados pela ONU.

Corroborando o cuidado com a natureza, a forma de produção agroecológica é um dos principais pilares e objetivos do MST, aliado a isso, a procura por alimentos saudáveis está cada vez mais presente na mentalidade popular. Para Valadão e Moreira (2009, p. 2844) "a agroecologia assume para o MST a perspectiva de uma outra forma de relação das pessoas com o mundo natural, não mercantil, mas sim, construir uma sociedade que atenda às necessidades dos seres humanos sem degradar os recursos naturais.".

A produção agroecológica foi muito incentivada pelos movimentos sociais, sendo que no ano de 2000, o MST adotou a agroecologia como linha política de ação, e a partir desse momento tornou-se um dos principais promotores do modelo (NIEDERLE et al., 2019).

Proporcionar melhores condições de vida à comunidade e comercializar produtos saudáveis não é tarefa fácil, pois o modelo de agricultura baseada em monocultivos para a exportação é predominante no território brasileiro. Esse modelo agrícola é contrário à produção agroecológica, bem como à implantação da reforma agrária. Em contrapartida, a reforma agrária no Brasil visa a produção de alimentos saudáveis, sem a utilização de agrotóxicos ou alimentos geneticamente modificados (REFORMA, 2018).

Essa produção de alimentos sem a utilização de agrotóxicos, chamadas de agricultura sustentável, além de contribuir para uma produção de alimentos saudáveis, também pode reduzir os impactos ambientais, e ainda trazer retorno financeiro necessário para atender as necessidades sociais dos produtores (ALTIERI, 2004).

Diante do exposto, objetivou-se analisar como a reforma agrária pode promover o desenvolvimento rural sustentável no assentamento Valmir Mota de Oliveira, situado na cidade de Cascavel, no Oeste do Paraná.

\section{MATERIAL E MÉTODOS}

Essa investigação constitui-se de um estudo de caso, realizada no assentamento Valmir Mota, em Cascavel no Oeste do Paraná, que de acordo com o Instituto Brasileiro de Geografia e Estatística (IBGE, 2017) possui uma população estimada de aproximadamente 319.608 pessoas, Índice de Desenvolvimento Humano (IDH, 2010) de 0,782, Produto Interno Bruto (PIB) em 2015 estimado em $\mathrm{R} \$ 32.372,08$ e o principal setor econômico é o agronegócio com mais de 4.000 estabelecimentos agropecuários, onde também predominam a indústria e o comércio.

As informações foram coletadas através de entrevistas semiestruturadas com seis líderes do assentamento, em abril de 2018, durante visita técnica realizada no assentamento. O questionário contava com 15 perguntas abertas, que propiciaram a livre discussão entre os participantes, porém focadas nos objetivos de desenvolvimento sustentável propostos pela ONU. Participaram da reunião líderes do assentamento, da cooperativa, responsáveis pelas áreas de produção e comercialização além do diretor do colégio existente. As entrevistas foram gravadas com autorização dos participantes, para posterior análise mais detalhada dos diálogos e informações.

A análise dos dados foi feita de forma qualitativa, comparando as falas dos assentados e a observação realizada in loco com os objetivos de desenvolvimento sustentável.

\section{RESULTADOS E DISCUSSÃO}

No acampamento residem 83 famílias, provenientes de vários acampamentos das diferentes regiões do estado do 
Paraná e do Paraguai. As Unidades de Produção Camponesa (Lotes Rurais do Assentamento) possuem em média 3 alqueires (7,26 hectares), entre as famílias assentadas, aproximadamente 59 casas de $43 \mathrm{~m}^{2}$ cada, que foram construídas através de financiamentos bancários específico para a modalidade rural. A construção das moradias da comunidade segue um modelo padronizado pelo projeto de assentamento do Ministério do Desenvolvimento Agrário (MDA), para se adequar ao financiamento. Além dos 83 lotes, o Assentamento possui uma área comunitária para auto sustentação, onde está a sede da Cooperativa e projeta-se futuramente instalar uma unidade de produção de leite.

Dentro do assentamento estão instaladas duas escolas: uma municipal (matutino) e outra estadual (vespertino), atendendo os estudantes do assentamento e das áreas rurais próximas. Inicialmente a escola foi construída pelos próprios moradores, com materiais precários, sem paredes laterais e com chão batido, sendo posteriormente melhorada a estrutura.

A proposta pedagógica das escolas segue as diretrizes do projeto educacional do MST, que propõe atender os anseios e as necessidades das famílias camponesas de educar as pessoas que trabalham no campo, para se articularem, se organizarem e assumir a condição de protagonista da direção de seu destino. As escolas atendem cerca de 220 educandos.

No planejamento inicial do assentamento, baseado no estudo do próprio MST, percebeu-se a necessidade de inovação, assim, com lotes menores do que outros assentamentos, poderiam desincentivar a monocultura. No formato reduzido dos lotes, seria priorizada a plantação agroecológica, com foco na diversidade de culturas. Essa escolha pela agroecologia foi fundamentada no Plano de Desenvolvimento do Assentamento (PDA). A produção não se mantém $100 \%$ agroecológica, pois entendeu-se que exigiria um tempo até que o mercado fosse conquistado e nesse tempo as famílias precisavam remunerar seu trabalho para sobreviverem. Conforme um assentado:

"Abrimos a proposta para não romper o diálogo. Uma das coisas interessantes do movimento é que nós sempre zelamos pela comunidade" (Entrevistado Assentado, 6 de abril de 2018).

Nesse mesmo objetivo de garantir a estadia das famílias, permitiu-se que alguns dos membros da família trabalhassem fora do lote, para trazer renda enquanto a produção não estava alavancada.

A aquisição de crédito é um fator limitante para o assentamento e as famílias não têm nenhum tipo de acesso a recursos para financiar suas produções. Apenas $10 \%$ das famílias conseguiram que o INCRA liberasse a Declaração de Aptidão ao Pronaf (DAP), que é documento essencial para ter acesso ao crédito. O financiamento é importante para construção de vários itens faltantes no assentamento, como estradas, poços artesianos e as moradias restantes. A água utilizada é extraída de mini poços construídos pelos próprios moradores.

Outro desafio para os produtores é a forma de comercialização da produção excedente. A produção é feita essencialmente para auto sustento, e o excedente é revendido em feiras, na Unioeste e em frente à Catedral de Cascavel. Conforme o depoimento de uma militante:
"Hoje o assentamento tem muita proposta de feira tanto como na região né mas a gente não tem tanta estrutura e pernas para estar participando de todas." (Entrevistado, militante, 6 de abril de 2018).

Um dos objetivos é participar da feira do produtor, porém, muitos já se inscreveram e não conseguiram vagas. Para os trabalhadores que estão produzindo de forma convencional, soja e milho não agroecológicos, o entendimento das lideranças é de que o mercado do agronegócio já está melhor organizado, ou seja, aquilo que o produtor planta e colhe ele consegue vender. Já verduras e legumes, não há a garantia de venda, não tem escala e precisa ter uma organização maior. Para facilitar a negociação dos produtos, recentemente foi aberta a Cooperativa de Produção e Comercialização da Agricultura Familiar e Reforma Agrária (COPCRAFT) com sede no assentamento, através dela, está sendo feita a venda institucional de alguns produtos pelo Programa Nacional de Alimentação Escolar (PNAE).

Apesar das dificuldades enfrentadas, os assentados têm consciência das vantagens obtidas pelo fato de a terra ser de boa qualidade e estarem próximos a uma cidade grande como Cascavel. Além disso, em análises sobre a rentabilidade de produtos advindos da monocultura, perceberam que o excedente é muito pequeno, já que os lotes são pequenos, não permitindo a produção em larga escala. Outro canal de revenda é o próprio local de produção, quando os consumidores procuram diretamente o assentamento para compra, porém, em alguns casos esses compradores são na verdade revendedores, que compram por um preço baixo e revendem visando um lucro maior. Ainda existe a venda direta na rua, quando o trabalhador coloca o produto no seu próprio carro e vai para rua comercializar. Um dos planos para o futuro é a abertura de um mercado municipal no centro de Cascavel, de produtos agroecológicos, projeto que já conta com o apoio da prefeitura que cedeu recentemente um espaço para isso.

Grande parte da produção gira em torno da cultura leiteira. A escolha foi devido ao planejamento feito pelo PDA, pela facilidade e necessidade de pouco investimento, já que o crédito ainda não foi liberado para as famílias. A maioria da produção é entregue em laticínios e uma parte é comercializada através das feiras. Apesar do leite ser o carro chefe, a produção hoje é extremamente diversificada, contendo os seguintes produtos: leite, queijo, frango, ovos, tubérculos em geral (mandioca, cenoura, beterraba, batata doce, nabo e outros), legumes variados (chuchu, abóboras, berinjela, pepino, caxi, maxixe), hortaliças (alface, rúcula, couve), carne (suíno, carneiro), plantas alimentícias não convencionais (PANC's), , como almeirão roxo, caramoela), frutas (cítricos, figo, banana, pêssego, maracujá, morango e outros), temperos (alho e temperos de folha, como cebolinha e salsa) entre outros produtos. Algumas frutas estão sendo produzidas em sistemas agroflorestais, iniciados há dois anos e que pouco a pouco tem maior aceitação das famílias. A escolha do que será cultivado, é feita pelo próprio produtor, porém, ocorre um planejamento com as famílias, para que não falte produção para entrega ao PNAE e nas feiras. Existem também demandas recolhidas pela equipe que trabalha nas feiras, quando algum consumidor 
demanda certo produto, a equipe conversa com as famílias para ver quem se habilita a produzi-lo.

Para capacitação, sempre que necessário o assentamento busca por parcerias. Possuem assistência técnica por convênios como o Centro de Apoio e Promoção da Agroecologia (CAPA/ITAIPU) com sede em Marechal Cândido Rondon, vinculado à Igreja Luterana. O Grupo da Rede Ecovida de Agroecologia já certificou 14 agricultores no assentamento Valmir Mota.

Em relação à formação da renda das famílias, estas provem em parte da produção de alimentos, alguns assentados trabalham na escola, sendo concursados em nível de graduação, outros trabalham em empregos temporários próximos à área do assentamento, em funções como saqueiro, serviços gerais, pedreiro entre outras. Algumas famílias recebem bolsa família, não há levantamento ao certo de quantas são, mas conforme depoimento de um assentado, no passado o número já foi maior, o que pode significar relativo aumento das condições econômicas de algumas famílias. Várias famílias já conseguiram abrir mão do benefício, pois, conseguem garantir seu sustento através do seu trabalho, seja na propriedade ou em outra função complementar. Percebe-se também que muitos assentados resolveram complementar seus conhecimentos e auxiliar no desenvolvimento do assentamento cursando cursos de graduação e nível técnico disponíveis nos centros urbanos.

Em relação às atividades de lazer e esporte, os militantes entendem que é necessário investir em infraestrutura, para que isso motive as famílias a permanecerem no campo. Existe um campo de futebol, porém, o mesmo não está gramado ainda e não há uma quadra poliesportiva. O lazer se dá através de reuniões de família, festividades religiosas e eventuais bailes.

A coleta de lixo é efetuada, através de um convênio com a prefeitura, onde os moradores levam o lixo até um depósito que fica próxima à estrada e a prefeitura recolhe. As estradas estão em boas condições de tráfego, mas foi necessária a intervenção da prefeitura para que os ônibus escolares pudessem circular. $\mathrm{O}$ atendimento de saúde é feito através do posto de saúde, que fica em São João d'Oeste, distando cerca de $18 \mathrm{~km}$ do assentamento.

O Assentamento Valmir Mota segue as diretrizes do PDA, que tem algumas premissas inerentes ao Movimento sem Terra. Outros estudos foram encontrados sobre o estudo do desenvolvimento sustentável em assentamentos de reforma agrária, porém nenhum sob a ótica dos 17 ODS's propostos pela ONU.

Em estudo realizado em assentamentos da região amazônica, foram analisados fatores que podem demonstrar o desenvolvimento sustentável, tais como: modificações no solo, sistemas de produção, características socioeconômicas e qualidade de vida. $\mathrm{O}$ resultado final demonstrou que houve o desenvolvimento, mas mais focado na qualidade de vida da população, porém com impacto negativo para o meio ambiente (SARTRE et al., 2016).

Outro estudo realizado em assentamentos no estado do Pará analisou o desenvolvimento sustentável, utilizando o "barômetro da sustentabilidade", que equilibra indicadores de aspecto humano e ecossistêmico. Na dimensão social foram considerados indicadores relativos à educação, saúde, moradia e população. $\mathrm{Na}$ dimensão econômica foi tratada da renda e comércio. Na dimensão organizacional foi verificada a questão das parcerias institucionais e na dimensão ambiental foram analisados os temas água e terra. A conclusão dos autores foi que os assentamentos promovem o desenvolvimento, variando conforme o modelo de assentamento. Em alguns casos falta investimento em água potável e energia elétrica, afetando a qualidade de vida. O meio ambiente continua sendo degradado, necessitando também de instrução para os assentados (SILVA; VIEIRA, 2016).

Após análise do assentamento foi verificado que o mesmo atende 8 objetivos de desenvolvimento sustentável.

\section{Erradicação da pobreza}

O ODS 1 tem como objetivo acabar com a pobreza em todas as suas formas, em todos os lugares. A reforma agrária pode promover melhor remuneração ao trabalhador rural, diminuindo os índices de migrações. No assentamento Valmir Mota ocorreu o incremento da renda dos moradores, inclusive com alguns parando de depender de programas de auxílio governamental.

\section{Fome zero e agricultura sustentável}

O ODS 2 tem como objetivo acabar com a fome, alcançar a segurança alimentar e melhoria da nutrição e promover a agricultura sustentável. O assentamento Valmir Mota faz isso de várias formas, produzindo alimentos para seu próprio consumo, comercializando o excedente por um preço acessível ao restante da população, produzindo de forma sustentável, através da agroecologia.

\section{Saúde e bem-estar}

O ODS 3 tem como objetivo assegurar uma vida saudável e promover o bem-estar para todas e todos, em todas as idades. Através da produção agroecológica adotada no assentamento estudado é possível viver sem a interferência de agrotóxicos, o que se reflete na alteração de humor que os produtores têm em saber que estão em contato com suas origens, produzindo algo saudável para suas famílias e para a população.

\section{Educação de qualidade}

O ODS 4 tem como objetivo assegurar a educação inclusiva e equitativa e de qualidade, e promover oportunidades de aprendizagem ao longo da vida para todas e todos. O assentamento Valmir Mota possui dentro de sua estrutura duas escolas com projeto pedagógico específico alunos que vivem no meio rural. Além disso, existe um incentivo ao estudo continuado, universitário ou técnico.

\section{Trabalho decente e crescimento econômico}

O ODS 8 tem como objetivo promover o crescimento econômico sustentado, inclusivo e sustentável, emprego pleno e produtivo e trabalho decente para todas e todos. Além de proporcionar emprego e renda para as famílias assentadas, a comunidade do Valmir Mota atinge esse objetivo ao produzir com diversificação e inovação, proporcionando trabalho decente e digno para jovens, homens e mulheres.

\section{Redução das desigualdades}

O ODS 10 tem como objetivo reduzir a desigualdade dentro dos países e entre eles. A reforma agrária é uma forma 
de reduzir a desigualdade através da distribuição justa de terras. Além disso, outra forma de redução das desigualdades é através do trabalho, já que com isso é possível aumentar a renda das famílias e também proporcionar maior autonomia aos produtores, promovendo a inclusão social, econômica e política. Nesse sentido o assentamento também consegue ter um resultado positivo.

\section{Cidades e comunidades sustentáveis}

O ODS 11 tem como objetivo tornar as cidades e os assentamentos humanos inclusivos, seguros, resilientes e sustentáveis. O assentamento Valmir Mota faz isso ao salvaguardar patrimônios naturais, auxiliando na redução de impacto ambiental. Além disso, apoia as relações econômicas, sociais e ambientais entre áreas urbanas e rurais.

\section{Consumo e produção responsáveis}

O ODS 12 tem como objetivo assegurar padrões de produção e de consumo sustentáveis. $\mathrm{O}$ assentamento faz isso realizar a gestão sustentável e uso eficiente dos recursos naturais. Atinge esse objetivo também ao produzir sem agrotóxico, garantindo um manejo ambientalmente saudável.

Conforme observado e analisado, o assentamento Valmir Mota está em conformidade com 8 dos 17 objetivos sustentáveis. Pode-se dizer que atinge uma grande parte desses objetivos, através do formato como o assentamento é constituído, bem como pela própria escolha da agroecologia como forma de produção.

A organização social e produção agrícola observada no assentamento comprova que o acesso à terra por estes camponeses promoveu o desenvolvimento social dos assentados e o desenvolvimento regional da área, que agora abriga, gera renda e trabalho para cerca de 83 famílias. Apesar de todas as dificuldades da produção agroecológica de pequena escala e do acesso aos mercados da agricultura familiar, do pouco volume de crédito dos camponeses, as famílias conseguem produzir alimentos de qualidade e vender o excedente em feiras da cidade e no próprio assentamento. O desenvolvimento de uma cooperativa no assentamento contribuiu muito para a organização dos agricultores e para a descoberta de canais de comercialização. De fato, a cooperativa promoveu a geração de renda através de vendas em cadeias curtas, também permitindo o importante acesso ao mercado institucional, através da entrega de alimentos para a merenda escolar, via PNAE.

A escolha pela produção de forma agroecológica ainda não atingiu a abrangência planejada no início da ocupação da área. Atualmente, com a adequação das áreas, o aprimoramento técnico dos agricultores nas técnicas agroecológicas, os assentados esperam fortalecer suas bases produtivas e construir mercados, com o objetivo de, no futuro, atingir $100 \%$ de produção agroecológica no assentamento.

Considerando os fortes laços de associação e cooperação entre os membros do movimento que habitam no local, a geração de renda através de uma produção agrícola de qualidade, com um comércio embasado em uma econômica solidária e a preservação ambiental, demonstra que a participação social dos camponeses e a dedicação por uma agricultura ecológica, contribui para a promoção de um desenvolvimento rural sustentável, que contemple o desenvolvimento das dimensões econômica, social e ambiental.

É possível afirmar através da observação de um assentamento que outros também tem a possibilidade de promover o desenvolvimento sustentável, como visto em outros estudos (SARTRE et al., 2016; SILVA; VIEIRA, 2016). Porém tanto no presente estudo como nos outros analisados, existe um longo caminho a ser percorrido. Em todos os casos estudados é necessário maior esforço para que os assentamentos consigam atingir o pleno desenvolvimento, contando com políticas públicas focadas e maiores investimentos.

\section{CONCLUSÕES}

O assentamento Valmir Motta consegue corroborar com 8 dos Objetivos de Desenvolvimento Sustentável propostos pela ONU através das suas ações voltadas para uma agricultura sustentável e bem estar dos seus moradores. Percebe-se, portanto, que é possível que os assentamentos da reforma agrária promovam o desenvolvimento sustentável, e formem o suporte para a mudança proposta pela a agenda 2030 .

\section{REFERÊNCIAS}

ALTIERI, M. Agroecologia: a dinâmica produtiva da agricultura sustentável: 4. ed. Porto Alegre: Editora da UFRGS, 2004.

BRASIL. Lei 4.504 de 30 de novembro de 1964. Dispõe sobre o Estatuto da Terra e dá outras providências. Disponível em: <http://www.planalto.gov.br/ccivil_03/leis/14504.htm>. Acesso em: 03 maio 2018.

IBGE. Instituto Brasileiro de Geografia e Estatística. IBGE Cidades: Cascavel. $2017 . \quad$ Disponível em: <https://cidades.ibge.gov.br/brasil/pr/cascavel/panorama>, Acesso em 03 maio 2018.

MARTINS, J. S. Os camponeses e a política no Brasil. Rio de Janeiro: Editora Vozes Ltda, 1981.

NIEDERLE, P. A.; SABOURIN, E.; SCHMITT, C. J.; ÁVILA, M. L. de; PETERSEN, P. A trajetória brasileira de construção de políticas públicas para a agroecologia. Redes, v. 24, n. 1, p. 270-291, 2019. 10.17058/redes.v24i1.13035

ONU. ORGANIZAÇÃO DAS NAÇÕES UNIDAS. Objetivos de desenvolvimento sustentável. Disponível em: <https://nacoesunidas.org/pos2015/>. Acesso em 17 jul. 2018.

REFORMA. Reforma agrária no Brasil. Disponível em: <http://reforma-agraria-no-brasil.info/>. Acesso em: 03 maio 2018.

SANTOS, C. B. R. A aplicação do programa nacional de produção e uso do biodiesel na agricultura camponesa em áreas de de Reforma Agrária. Revista Cerrados, v. 15, n. 2, p. $162-$ 180, 2017. 10.22238/rc24482692v15n22017p162a180 
SARTRE, X. A.; OSZWALD, J.; VEIGA, I.; CASTRO, M.; ASSIS, W. S.; MICHELLOTI, F.; ROCHA, C.; SOUZA, H.; SEBILlE, P.; DOLÉDEC, S.; LAVELLE, P. Sustainable development policies and the spread of land-sharing practices A statistical assessment in a frontier region of the Brazilian Amazon. Journal of Rural Studies, v. 48, , p. 65-76, 2016. 10.1016/j.jrurstud.2016.09.009

SILVA, V. C. S.; VIEIRA, I. C. G. Barômetro da Sustentabilidade aplicado a assentamentos rurais do leste do Estado do Pará, Brasil. Desenvolvimento e Meio Ambiente, v. 36, p. 201-221, 2016. 10.5380/dma.v36i0.39957

SILVA, E. N.; AMARAL, R. F. do; MACIEL, H. M. CAMPESINATO E REFORMA AGRÁRIA: UM DEBATE CONTEMPORÂNEO. Perspectivas online:hum.\& sociais aplicadas, v. 15, n. 6, p. 1-13, 2016. 10.25242/88766152016969

SILVA, M. P. N. S.; MIRANDA, R. S.; RODRIGUES, A. B. A questão agrária brasileira revisitada. Revista Verde de Agroecologia e desenvolvimento Sustentável, v. 7, n. 1, p. 48 54, 2012.

VALADÃO, A. C.; MOREIRA, S. S. Reflexões sobre a compreensão de agroecologia pelo movimento dos trabalhadores rurais sem terra. Cadernos de Agroecologia, , v.4. n.1, 2009. 